\title{
The Enterprise Derivative Application: Flexible Software for Optimizing Manufacturing Processes
}

November 2008

Prepared by

Glenn O. Allgood

Richard C. Ward

John R. Knox

Oak Ridge National Laboratory

One Bethel Valley Rd.

P.O. Box 2008

Oak Ridge, Tennessee 37831-6085

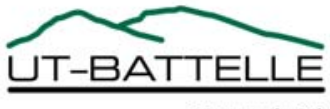




\section{DOCUMENT AVAILABILITY}

Reports produced after January 1, 1996, are generally available free via the U.S. Department of Energy (DOE) Information Bridge.

Web site http://www.osti.gov/bridge

Reports produced before January 1, 1996, may be purchased by members of the public from the following source.

National Technical Information Service

5285 Port Royal Road

Springfield, VA 22161

Telephone 703-605-6000 (1-800-553-6847)

TDD 703-487-4639

Fax 703-605-6900

E-mail info@ntis.gov

Web site http://www.ntis.gov/support/ordernowabout.htm

Reports are available to DOE employees, DOE contractors, Energy Technology Data

Exchange (ETDE) representatives, and International Nuclear Information System (INIS)

representatives from the following source.

Office of Scientific and Technical Information

P.O. Box 62

Oak Ridge, TN 37831

Telephone 865-576-8401

Fax 865-576-5728

E-mail reports@osti.gov

Web site http://www.osti.gov/contact.html

This report was prepared as an account of work sponsored by an agency of the United States Government. Neither the United States Government nor any agency thereof, nor any of their employees, makes any warranty, express or implied, or assumes any legal liability or responsibility for the accuracy, completeness, or usefulness of any information, apparatus, product, or process disclosed, or represents that its use would not infringe privately owned rights. Reference herein to any specific commercial product, process, or service by trade name, trademark, manufacturer, or otherwise, does not necessarily constitute or imply its endorsement, recommendation, or favoring by the United States Government or any agency thereof. The views and opinions of authors expressed herein do not necessarily state or reflect those of the United States Government or any agency thereof. 


\title{
The Enterprise Derivative Application: Flexible Software for Optimizing Manufacturing Processes
}

\author{
Glenn O. Allgood, Ph.D., P.E., Richard C. Ward, Ph.D., and John R. Knox \\ Modeling and Simulation Group \\ Computational Sciences and Engineering Division
}

November 2008

Research sponsored by the U.S. Department of Energy, Office of Energy Efficiency and Renewable Energy, Office of Industrial Technologies, Value Chain Analysis Program, under Contract DE-AC05-00OR22725 with UT-Battelle, LLC

Prepared by

OAK RIDGE NATIONAL LABORATORY

Oak Ridge, Tennessee 37831-6006 managed by

UT-BATTELLE, LLC

for the

U.S. DEPARTMENT OF ENERGY under contract DE-AC05-00OR22725 



\section{Table of Contents}

\section{Page}

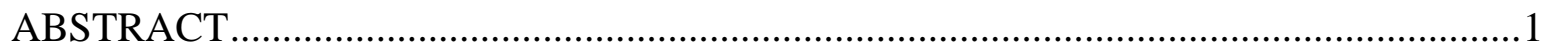

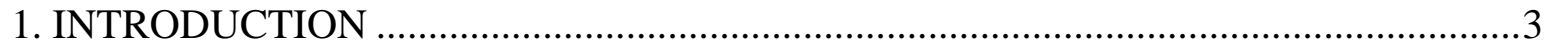

2. ENTERPRISE-DERIVATIVE ANALYSIS ............................................................

3. STEPS OF THE ENTERPRISE DERIVATIVE APPLICATION ................................7

3.1 DEVELOPING THE PROCESS FLOW .............................................................

3.2 COMPUTING THE ENTERPRISE SENSITIVITY PARAMETERS ......................8

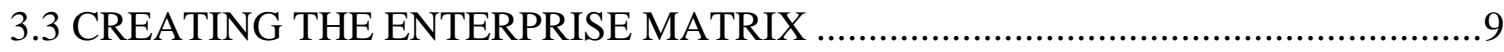

3.2 CONDUCTING A TECHNOLOGY ASSESSMENT AND IMPACT ANALYSIS..9

3.5 OPTIMIZING TECHNOLOGICAL CHANGES ..............................................11

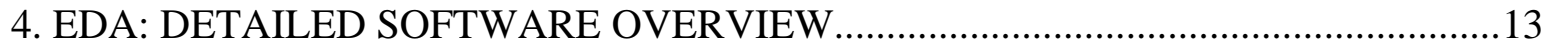

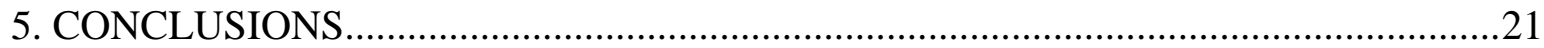

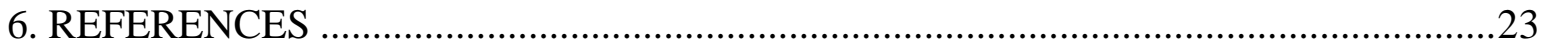

APPENDIX A: SET UP FORM FOR EDA …....................................................... A-1

APPENDIX B: FIX FOR RUNNING APPLICATION .................................................... 



\title{
Enterprise Derivative Application: Flexible Software for Optimizing Manufacturing Processes
}

\begin{abstract}
The Enterprise Derivative Application (EDA) implements the enterprise-derivative analysis for optimization of an industrial process. ${ }^{1}$ It is a tool to help industry planners choose the most productive way of manufacturing their products while minimizing their cost. Developed in Microsoft (MS) Access, the application allows users to input initial data ranging from raw material to variable costs and enables the tracking of specific information as material is passed from one process to another.
\end{abstract}

Energy-derivative analysis is based on calculation of sensitivity parameters. For the specific application to a steel production process these include: the cost to product sensitivity, the product to energy sensitivity, the energy to efficiency sensitivity, and the efficiency to cost sensitivity. Using the EDA for all processes, the user can display a particular sensitivity or all sensitivities can be compared for all processes.

Although energy-derivative analysis was originally designed for use by the steel industry, it is flexible enough to be applied to many other industrial processes. Examples of processes where energy-derivative analysis would prove useful are wireless monitoring of processes in the petroleum cracking industry and wireless monitoring of motor failure for determining the optimum time to replace motor parts.

One advantage of the MS Access-based application is its flexibility in defining the process flow and establishing the relationships between parent and child process and products resulting from a process. Due to the general design of the program, a process can be anything that occurs over time with resulting output (products). So the application can be easily modified to many different industrial and organizational environments. Another advantage is the flexibility of defining sensitivity parameters. Sensitivities can be determined between all possible variables in the process flow as a function of time. Thus the dynamic development of the process can be tracked over time and optimized. EDA is a uniquely flexible and efficient way for planners to choose the most productive way of optimizing production while minimizing costs.

The purpose of this document is to describe energy-derivative analysis and the operation of the application. The first section is an introduction of the concept, followed in Sect. 2 by a detailed description of the analysis approach. The third section provides a general overview of the operation of the application. The detailed description of the application is described in Sect. 4, using the steel mill operation as an example. Conclusions regarding the utility of the EDA and the effectiveness of the implementation follow in Sect. 5. Appendix A describes details of setting up the process flow model and App. B provides information on overcoming an error that occurred in using the application on a PC that did not have Visual Basic installed. 



\section{INTRODUCTION}

In today's manufacturing environment, systems and equipment are being asked to perform at levels not thought possible a decade ago. The intent is to push process operations, product quality, and equipment reliability to unprecedented levels while pursuing cost reduction initiatives. Industries see a tremendous amount of uncertainty associated with calculating total process impact and fear the mysticism that may be required for such a venture. What is needed is a methodology and approach that takes the guesswork out of calculating the total cost/benefit for any new technology or innovation. The energy-derivative analysis provides a solution to this problem - a new tool for developing and managing investment strategies and risks.

Energy-derivative analysis mitigates risks by first identifying the potential benefits for all processes and sub-processes associated with new technologies or innovations. This is realized by calculating approximations to the first order sensitivity parameters (first derivatives) obtained from using a Taylor Series expansion about the system's operating point. These sensitivity parameters are invariant economic and operational indicators that quantify the impact of any proposed technology in terms of material throughput, efficiency changes, energy use, environmental effects, and costs. The model then develops a set of coupled equations from these parameters that links the entire enterprise system together, so that total impact can be calculated. The key to the model is the evaluation of the sensitivity parameters.

Energy-derivative analysis will have a major impact on business and engineering decisions to select and incorporate new technologies and innovations into processes. The metrics or measures of performance that are derived from the model are well defined and can be used to track technology impacts across the enterprise and over extended periods of operation.

The Enterprise Derivative Application (EDA) implements energy-derivative analysis for optimization of an industrial process. It is a tool to help industry planners choose the most productive way of making their products while minimizing their cost. Developed using Microsoft (MS) Access and Visual Basic, the application allows users to input initial data ranging from raw material to variable costs and enables the tracking of specific information as material is passed from one process to another.

In this paper we outline the energy-derivative analysis with specific application to the process flow in a mini-mill steel manufacturing ${ }^{2}$. This example consists of twelve process producing five products. Screenshots of the MS-Access application will demonstrate how energy-derivative analysis has been implemented for this specific case.

Although energy-derivative analysis was originally designed for use by the steel industry, it is flexible enough to be applied to many other industrial processes. Examples of processes where energy-derivative analysis would prove useful are wireless monitoring of processes in the petroleum cracking industry and wireless monitoring of motor failure for determining the optimum time to replace motor parts.

One advantage of the MS Access-based EDA is its flexibility in defining the process flow and establishing the relationships between parent and child processes and products resulting from a process. Due to the general design of the program, a process can be anything that occurs over 
time with resulting output (products). So the application can be easily modified to many different industrial and organizational environments. Another advantage is the flexibility of defining sensitivity parameters. Sensitivities can be determined between all possible variables in the process flow as a function of time. Thus the dynamic development of the process can be tracked over time and optimized. The EDA is a uniquely flexible and efficient way for planners to choose the most productive way of optimizing production while minimizing costs. 


\section{ENTERPRISE-DERIVATIVE ANALYSIS}

The basis of EDA is the calculation of a set of enterprise-derivative sensitivity parameters that are used in a coupled set of equations to calculate the impacts on a process from a proposed technology or innovation. The assumption is that the proposed technology or innovations will not change the way manufacturing is made but will affect the operational efficiencies about is current operating point. Given this assumption, the process can then be modeled as a first-order Taylor Series expansion about the operating point with changes being influenced by the first differential of a derived benefit. Process gains (production, efficiency, energy, and quality) are estimated as incremental changes from the operating point. The mathematical formulation for any process gain, $\boldsymbol{f}$, is

$$
f(x)=f\left(x_{0}\right)+f^{\prime}\left(x_{0}\right)\left(x-x_{0}\right)+. .+\frac{f^{n}\left(X_{0}\right)\left(x-X_{O}\right)^{n}}{n !}+R n,
$$

where $X_{0}$ is the current plant operating point and $R n$ is a remainder and is ignored in this formulation. In this expansion, we are only interested in the first term, $f^{\prime}\left(x_{0}\right)$, which is the generalized differential approximation or enterprise-derivative sensitivity term.

The generalized differential approximation (sensitivity) is expanded in general terms as a linear combination of ratios of total differentials of the process changes due to technology innovations (i.e., product, energy, and efficiency). The total differential is:

$$
\Delta f_{\text {Tech }}=\frac{\partial E}{\partial \eta} \Delta \eta+\frac{\partial \eta}{\partial C} \Delta C+\frac{\partial C}{\partial \mathrm{P}} \Delta \mathrm{P}+\frac{\partial \mathrm{P}}{\partial E} \Delta E+\varepsilon
$$

where, $E, \eta, C, P$ are the energy, efficiency, savings, and product, respectively and $\varepsilon$ is the error associated with the approximation and is ignored in the EDA.

These sensitivity parameters are based on a total derivative calculation and are approximations to the first partial derivatives of a multiple variable function. The sensitivity parameters are defined below for reference.

$\frac{\partial E}{\partial \eta}$ is the change in process energy per unit change in efficiency,

$\frac{\partial \eta}{\partial C}$ is the change in process efficiency per unit change in costs, and

$\frac{\partial C}{\partial \mathrm{P}}$ is the change in process costs per unit change in product.

The remaining sensitivity parameter, $\frac{\partial \mathrm{P}}{\partial E}$, can be calculated directly or derived as ratios of other sensitivity parameters. 
Conducting an EDA involves the following four steps:

1. Develop the process flow.

2. Compute the sensitivity parameters of the enterprise.

3. Conduct a technology assessment and impact analysis.

4. Optimization (what-if strategies).

Each step will be described in detail for an example problem ${ }^{2}$ in the following sections. The example problem is process flow in mini-mill steel manufacturing consisting of the twelve processes:

Electric Arc Furnace $=>$ Ladle Metallurgy Station $=>$ Caster $=>$ Tunnel Furnace $=>$ Hot strip Mill (HSM). At this point the process splits

HSM $=>$ Acid Pickling $=>$ Cold Mill Reduction A => Galvanized

$\mathrm{HSM}=>$ Temper A.

Temper A then splits: Temper A => Cold Mill Reduction B or Temper A => Annealing => Temper B. 


\section{STEPS OF THE ENTERPRISE DERIVATIVE APPLICATION}

\subsection{DEVELOPING THE PROCESS FLOW}

A requirement for conducting an EDA is to develop a complete understanding of the process: its product flow; material changes; and procedural steps used in the making the product. This understanding also includes identifying energy use, material residence time, and maintenance and operational procedures. This microscopic view of the process is needed to resolve balance of plant issues and to help understand energy, material, and time management as it applies to the current process. In the course of conducting the EDA, a detailed process flow diagram is developed. Roll-ups from these process flow diagrams are then developed along with energy and time management diagrams. Some of the process variables extracted from the diagrams are used in the calculation of the first order Enterprise-Derivative sensitivity parameters.

In the EDA, the user can interactively design the process flow by dragging the process icons into place (Fig. 1). Likewise the user drags the Product icons where desired (in this example there are products out of the TF, GAL, TEMP A, TEMP B and CRM B processes. Once the user has specified the number of processes $m$ and products $n$ and connected the processes, the user must create the parent-child relationships, name the processes, and save the process flow. Note that in this example there are twelve processes and five products. But there is also a "Process zero" which is the initial feed. The diagram represents the flow of material from the initial feed to successive processes with production of products P1 through P5.

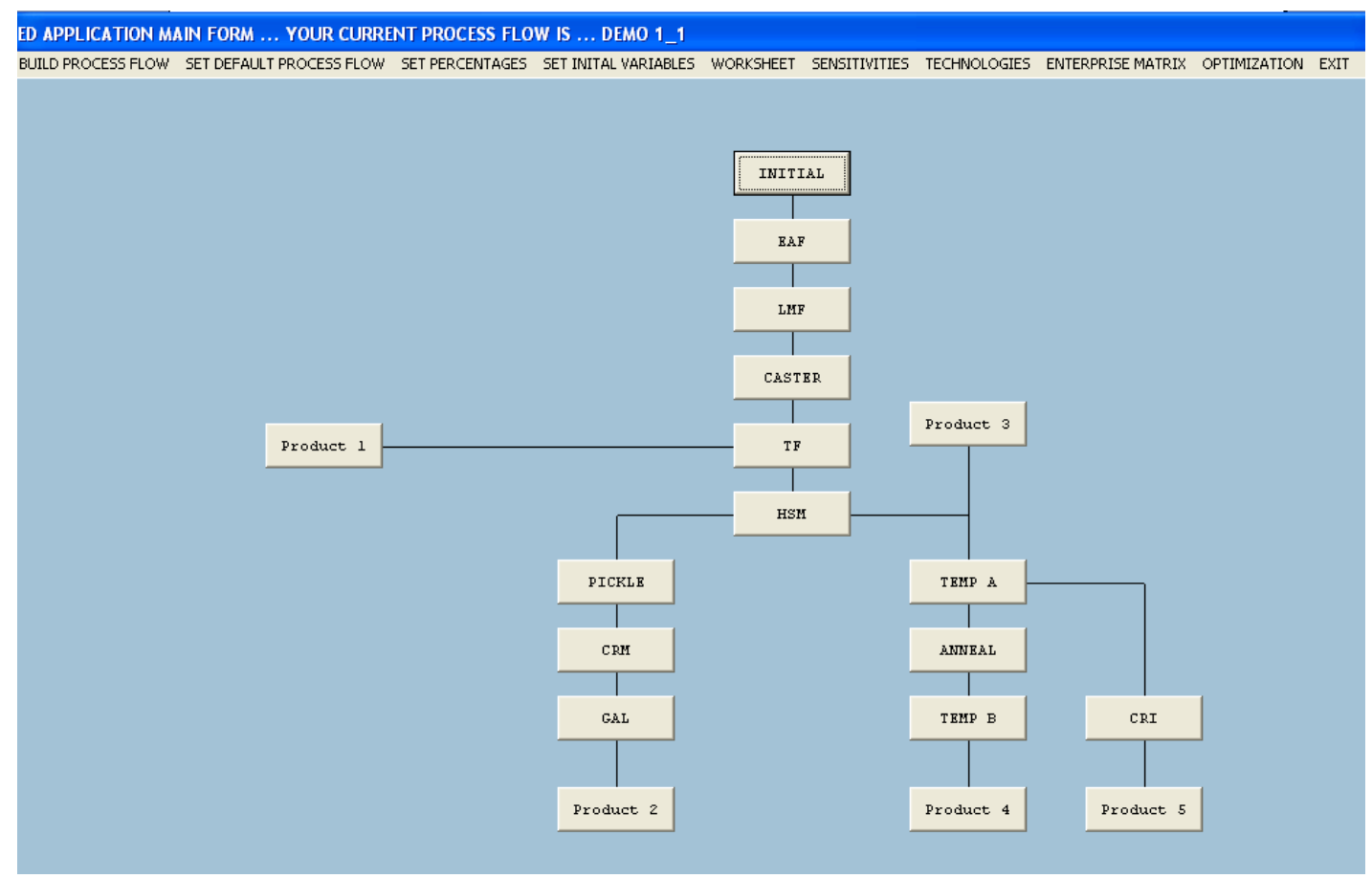

Fig. 1. EDA form for creating the process flow. To develop the process flow, the user drags process icons into place and connects processes in desired manner (see Appendix A for description). 


\subsection{COMPUTING THE ENTERPRISE SENSITIVITY PARAMETERS}

The next step is the computation of the sensitivity parameters. The user must first enter the Enterprise information for each process as shown in Fig. 2.

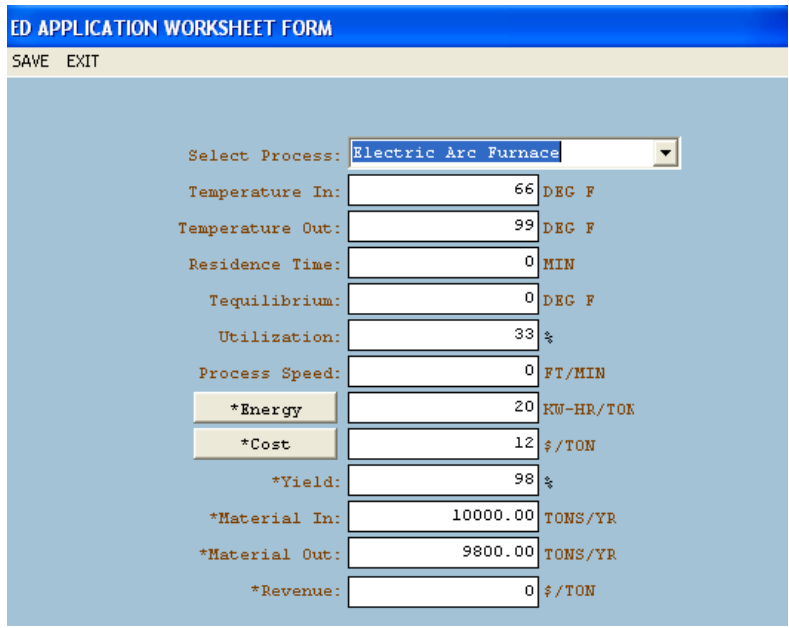

Fig. 2. On this form the user enters the Enterprise information consisting of required fields: energy, cost, maximum processing capacity, yield, and revenue.

This information includes costs, energy usage, and revenue for each product. Once this information is completed, the sensitivities are computed and displayed as shown in Fig. 3. This EDA Sensitivity form displays the sensitivity parameters for each associated process. The sensitivity parameters (and associated

ED APPLICATION SENSITIVITY FORM
CHART EXIT
\begin{tabular}{|l|c|c|c|c|c|c|}
\hline \multicolumn{1}{|c|}{ PROCESS } & DC/DP & DP/DE & DE/DN & DN/DC & DP/EC1 & DE/DC2 \\
\hline Electric Arc Furnace & 37.000 & 0.0500000000 & 4000.00 & 0.00013514 & 0.05000000 & 0.00000000 \\
\hline Ladle Ketallurgy Furnace & 55.755 & 0.0625000000 & 1568.00 & 0.00018302 & 0.12500000 & 0.12500000 \\
\hline Caster & 70.318 & 0.0454545455 & 4268.88 & 0.00007329 & 0.09090909 & 0.09090909 \\
\hline Tunnel Furnace & 83.753 & 0.0555555556 & 5134.30 & 0.00004186 & 0.11111111 & 0.11111111 \\
\hline Hot Strip Xill & 100.344 & 0.0454545455 & 7304.40 & 0.00003002 & 0.09090909 & 0.09090909 \\
\hline Pickle/0iler/Dryer & 115.525 & 0.0666666667 & 2510.06 & 0.00005173 & 0.12500000 & 0.14285714 \\
\hline Cold Reduction Xill & 132.220 & 0.0476190476 & 3734.96 & 0.00004252 & 0.10000000 & 0.09090909 \\
\hline Galvanized & 150.717 & 0.0526315789 & 388.61 & 0.00032439 & 0.09090909 & 0.12500000 \\
\hline Temper A & 112.525 & 0.0476190476 & 3514.08 & 0.00005311 & 0.09090909 & 0.10000000 \\
\hline Annealing & 125.005 & 0.0588235294 & 2299.49 & 0.00005914 & 0.10000000 & 0.14285714 \\
\hline Temper B & 142.584 & 0.0476190476 & 3238.22 & 0.00004548 & 0.09090909 & 0.10000000 \\
\hline Cold Reduction Inspection & 124.005 & 0.0625000000 & 2337.36 & 0.00005520 & 0.12500000 & 0.12500000 \\
\hline
\end{tabular}

Fig. 3. The sensitivity parameters are computed and displayed once the user has completed entering all the Enterprise information.

units) are the ones defined previously $\frac{\partial E}{\partial \eta}(\mathrm{kW}-\mathrm{h}), \frac{\partial \eta}{\partial C}\left(\$^{-1}\right), \frac{\partial C}{\partial \mathrm{P}}(\$ / \mathrm{ton}), \frac{\partial \mathrm{P}}{\partial E}$ (ton $\left./ \mathrm{kW}-\mathrm{h}\right)$, and two additional sensitivities which break the energy utilization into both an electricity sensitivity parameter, $\frac{\partial \mathrm{P}}{\partial E C 1}(\mathrm{ton} / \mathrm{kW}-\mathrm{h})$, and a natural gas sensitivity parameter, $\frac{\partial \mathrm{P}}{\partial E C 2}($ ton $/ \mathrm{kW}-\mathrm{h})$. 
The baseline operation can be expressed in an enterprise matrix (EM) which shows flow of material from one process to the next and of product produced. This matrix completely describes the baseline operation. The matrix can also be stated as ratios of material moved from one process from the next, in which case it is referred to as the R Matrix (RM).

The EM or RM represents the culmination of the enterprise-derivative computation. The EDA has all the information it needs to computer the status quo operation, the plant operating point. The user now moves on to conduct a technology assessment and impact analysis, where changes in technology are introduced and products produced by processes are increased or decreased and the impact analysis is made about the original plant operating point.

\subsection{CREATING THE ENTERPRISE MATRIX}

The user can select to display the Enterprise Matrix as shown in Fig. 4.

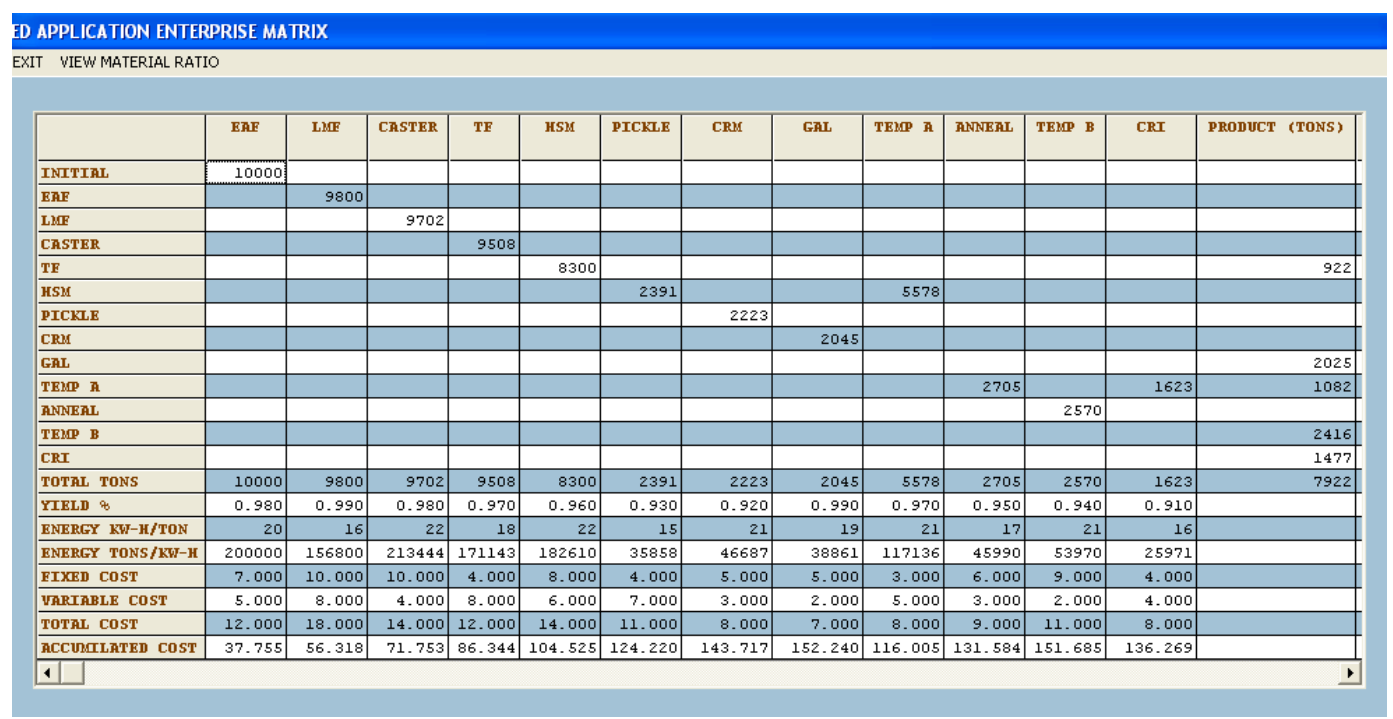

Fig. 4. Once the user has entered all the Enterprise information and the sensitivity parameters have been computed, the EM (products transferred from process to process in tons) or the RM (ratio of material moved from one process to the next) can be displayed. Here the EM is shown.

We see here that the EM is an overview of the enterprise-derivative analysis in matrix view. The top half of the screen shot shows the flow of material from one process to another while the bottom half shows the process parameters. At the right of the form, the product, revenue and profit are displayed. The user can select from this "Enterprise Matrix" view (for the EM), which shows transfer in terms of tons of material, to an "R Matrix" view (for the RM), in which the ratio of material moved from one process to another is displayed. To access this feature, the user clicks on the button in the lower right corner. This converts the top half of the form to reflect the material flow as a ratio.

\subsection{CONDUCTING A TECHNOLOGY ASSESSMENT AND IMPACT ANALYSIS}

Using the information extracted from the process flow diagrams, a technology assessment can be conducted for each manufacturer or company. Plant managers and technical representatives for 
each of the individual sub-processes are asked to sit in on a session to review the findings of the process flow activity. They are also asked to identify new technologies and needs (or innovations) that are considered important to enhancing their operational performance or increasing overall process efficiency. During the review, any proposed need or technology candidate is identified and listed along with its current operating profile, desired profile, and any figures of merit associated with its use. The amount of change in the product for this process for every specified technology modification is required by the program (Fig. 5). The identification of the operational impacts that these technologies will have on the enterprise/plant/process is included in this analysis. Other indicators of importance include: variance defined as labor, maintenance, or productivity; impact defined in terms of operations, throughput, or quality; and priority ranking defined in terms of high, medium, or low for the particular process step and numerical (1-10) as it would relate to the entire process. These additional indicators provide a measure of importance for each technology or innovation as determined by the plant and technology personnel.

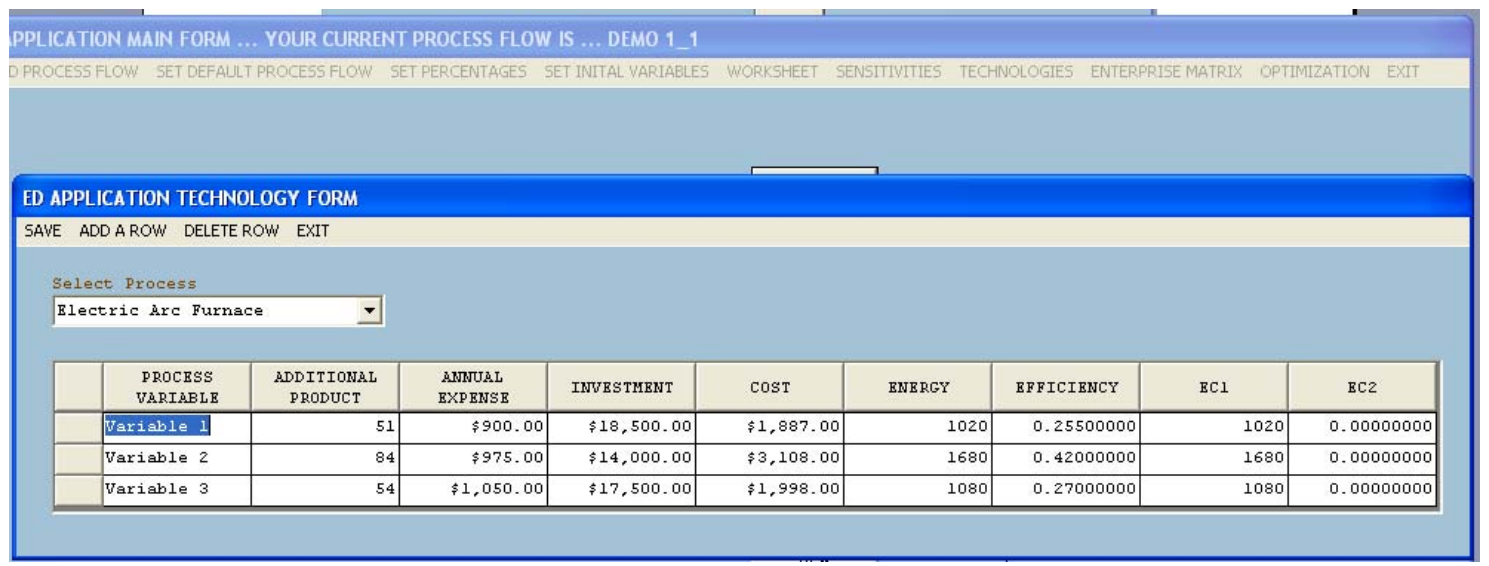

Fig. 5. Once the Enterprise has been defined, the user enters the desired technology improvements and their associated product increases (or decreases) for all technology modifications for each process. This form then displays the differential in the sensitivity parameters derived from the associated product change, using the previously computed sensitivity parameters.

The Technology Analysis form allows the user to add or delete new technologies, annual expenses, and investments for each process. After the new technologies and innovations have been identified along with their respective variance, impact, and priority ranking, their economic and process impacts are calculated for the enterprise system. These measures of performance will be in terms of cost saving or yield increases if it were deployed. During a typical study, usually one or the other is given.

Given these economic indicators, the model then calculates three additional parameters; energy, efficiency, and per-process cost savings. Energy savings are computed for electricity, natural gas, and for total energy. These parameters, along with other process data, are used in the subsequent analysis and comparison. 


\subsection{OPTIMIZING TECHNOLOGICAL CHANGES}

The last element in conducting the EDA is selecting the optimal mix of technologies based on some stated criteria. The optimization scheme implemented (algorithm or heuristic) will use the economic and process impacts derived from the energy-derivative analysis coupled with the energy-derivative sensitivity parameters to search for an optimal solution in the value space for a given set of hard and soft constraints. The different optimization approaches include:

Risk Analysis: Risk analysis will determine the process and economic impact of a new operational strategy. If only one operational strategy is to be analyzed, the process and economic impact analysis becomes a straightforward activity using the coupled equations of the enterprise model if the product mix ratios are maintained.

If more than one operational strategy is to be analyzed concurrently, the optimization model uses the enterprise's coupled equations to estimate changes in $f(x)$ assuming the same product mix ratios. As before, the EDA will also provide the parametric analysis figures for each operational strategy, and ultimately suggest the best implementation sequence for the given operational strategies.

Alternative Analysis: Alternative analysis deals with contrasting and comparing two or more operational strategies. The optimization module can calculate changes in $f(x)$ for each operational strategy using the coupled equations, and provide a ranking based on production cost savings, additional throughput and energy savings assuming the product mix ratios are not changed.

Enterprise Analysis: Enterprise-derivative analysis will select the operational strategy or group of operational strategies that will maximize or minimize an objective function given a set of criteria. Since the sensitivity parameters are invariant for each process regardless of the operational strategies, the module can optimize the enterprise through a two-step procedure: 1) the optimization algorithm will select the process or processes that meet a set of multi-goal criteria based on the information contained in the sensitivity parameters and 2) select the operational strategy or group of operational strategies that maximize the benefits of the process(es) as reflected by $f(x)$ and without violating the constraints.

The EDA presents the user with a form (Fig. 6) that shows the differences between the original process and sensitivity parameters and the optimized ones. Negative entries (colored red on the screen) signify a decrease in parameters and positive entries (colored blue on the screen) signify an increase in parameters.

The user can click on the ENTERPRISE MATRIX button on the Optimization form to view an optimized EM (Fig. 6) showing the difference in values due to optimization. 


\begin{tabular}{|c|c|c|c|c|c|c|c|c|c|c|c|c|c|c|c|}
\hline \multicolumn{16}{|c|}{ APPLICATION ... VIEW OPTIMIZED ENTERPRISE MATRIX } \\
\hline \multicolumn{16}{|l|}{ IT } \\
\hline \multicolumn{16}{|c|}{ 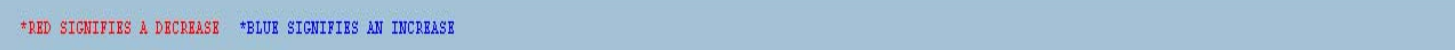 } \\
\hline \multicolumn{16}{|c|}{ Please choose a grid from below } \\
\hline \multicolumn{6}{|c|}{ View Optimized Bnterprise Hatrix } & 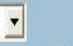 & & & & & & & & & \\
\hline & $\mathrm{BRF}$ & LIT & CASTER & $\mathrm{TF}$ & HSII & PICKLE & CRIS & GAL & TEM A & ANNERL & TEIP B & $\mathrm{CRI}$ & PRODUCT (TONS) & REVENOR (\$/TON) & PROPIT (\$/TON) \\
\hline INITIRL & 10000 & & & & & & & & & & & & & & \\
\hline EAP & & 9800 & & & & & & & & & & & & & \\
\hline LIF & & & 9702 & & & & & & & & & & & & \\
\hline CASTER & & & & 9508 & & & & & & & & & & & \\
\hline $\mathrm{TP}$ & & & & & 8341 & & & & & & & & 927 & $\$ 100.00$ & $\$ 12,949.36$ \\
\hline HSM & & & & & & 2415 & & & 5635 & & & & & & \\
\hline PICKLIE & & & & & & & 2246 & & & & & & & & \\
\hline $\mathrm{CRM}$ & & & & & & & & 2066 & & & & & & & \\
\hline GAL & & & & & & & & & & & & & 2045 & $\$ 165.00$ & $\$ 28,012.91$ \\
\hline TEM 凡 & & & & & & & & & & 2782 & & 1669 & 1113 & $\$ 135.00$ & $\$ 23,977.39$ \\
\hline ANNRAL & & & & & & & & & & & 2643 & & & & \\
\hline TEMP B & & & & & & & & & & & & & 2522 & $\$ 175.00$ & $\$ 70,980.57$ \\
\hline CRI & & & & & & & & & & & & & 1519 & $\$ 145.00$ & $\$ 17,519.38$ \\
\hline TOTAL TONS & 10000 & 9800 & 9702 & 9508 & 8341 & 2415 & 2246 & 2066 & 5635 & 2782 & 2643 & 1669 & 8126 & $\$ 720.00$ & $\$ 153,439.61$ \\
\hline YIELD \& & 0.980 & 0.990 & 0.980 & 0.975 & 0.965 & 0.930 & 0.920 & 0.990 & 0.988 & 0.950 & 0.954 & 0.910 & & & \\
\hline ENERGY KVI-H/TON & 20 & 16 & 22 & 18 & 22 & 15 & 21 & 19 & 21 & 17 & 21 & 16 & & & \\
\hline ENERGY TONS/KVI-H & 200000 & 156800 & 213444 & 171143 & 183501 & 36223 & 47162 & 39257 & 118328 & 47299 & 55507 & 26710 & 1295374 & & \\
\hline FIXED COST & 7.000 & 10.000 & 10.000 & \begin{tabular}{|l|}
4.100 \\
\end{tabular} & 8.081 & 4.000 & 5.000 & 5.000 & 3.312 & 6.000 & 9.197 & 4.000 & & & \\
\hline VARTABLE COST & 5.000 & 8.000 & 4.000 & \begin{tabular}{|l|}
8.000 \\
\end{tabular} & 6.000 & 7.000 & 3.000 & 2.000 & 5.000 & 3.000 & 2.000 & 4.000 & & & \\
\hline TOTAL COST & 12.000 & 18.000 & 14.000 & 12.100 & 14.081 & 11.000 & 8.000 & 7.000 & 8.312 & 9.000 & 11.197 & 8.000 & & & \\
\hline ACCUSILATED COST & 37.755 & 56.318 & 71.753 & \begin{tabular}{|l|}
86.027 \\
\end{tabular} & 103.733 & 123.369 & 142.792 & 151.305 & 113.455 & 128.901 & 146.851 & 133.468 & & & \\
\hline
\end{tabular}

Fig. 6. The EM showing the processes that increased product transfer between processes (shown using blue color font) with corresponding decreases in costs (shown using red font). 


\section{EDA: DETAILED SOFTWARE OVERVIEW}

After starting the application, the MAIN FORM (Fig. 1) loads displaying a process flow diagram that represents the flow of material from one process to another and the product, if any, a particular process might have.

For the initial use of the EDA, there is a series of steps to follow in order to properly populate the data needed for the EDA calculations. The order is:

1. Populate the process names, acronyms, and parent-child relationships by clicking on the BUILD PROCESS FLOW button at the top of the form. Documentation for this is found in the document EDA_SetUp.doc

2. Assign material flow, material yield, product yield, and maximum processing capacity by clicking on the SET PERCENTAGES button at the top of the form.

3. Assign initial starting values such as material, cost, etc., by clicking on the SET INITIAL VARIABLES button at the top of the form.

4. Complete the worksheet for all processes (i.e., cost, energy, etc) by clicking on the WORKSHEET button at the top of the form.

5. Assign any process variables (technologies), additional products, annual expenses, and investments a particular technology might have by clicking the TECHNOLOGIES button at the top of the form.

Once these criteria have been completed, the user can view other parts of the application such as the sensitivities, the enterprise matrix, and the optimization.

After the user has completed step one by building their process flow, they must set the default process flow by clicking on the SET DEFAULT PROCESS FLOW button at the top of the form.

The second criterion requirement is to determine the material percentages. To open the SET PERCENTAGES FORM, click on the SET PERCENTAGES button on the MAIN FORM. The SET PERCENTAGES FORM is displayed in a data grid. The material flow is the percent of material flowing from one process to another. The default material flow for all processes is $100 \%$. The only time a user should change the material ratio for a process is if it is a child in a split or if there is product for a process. For the example shown in Fig. 1, the SET PERCENTAGES FORM is seen below in Fig. 7. Process five is a parent of both process six and process nine. Process five (HSM) sends $30 \%$ of its material to Process six (PICKLE) and $70 \%$ to Process nine (TEMP A). NOTE: Percentages are entered as whole numbers instead of decimals. Processes that have all material going out to a product would have a material ratio equal to the material yield of that process. The material yield for a process is the material yield for that particular process. The product yield is the percent of material going to product. The Max Process Cap is the maximum cap in production of the process and is used in the optimization. 


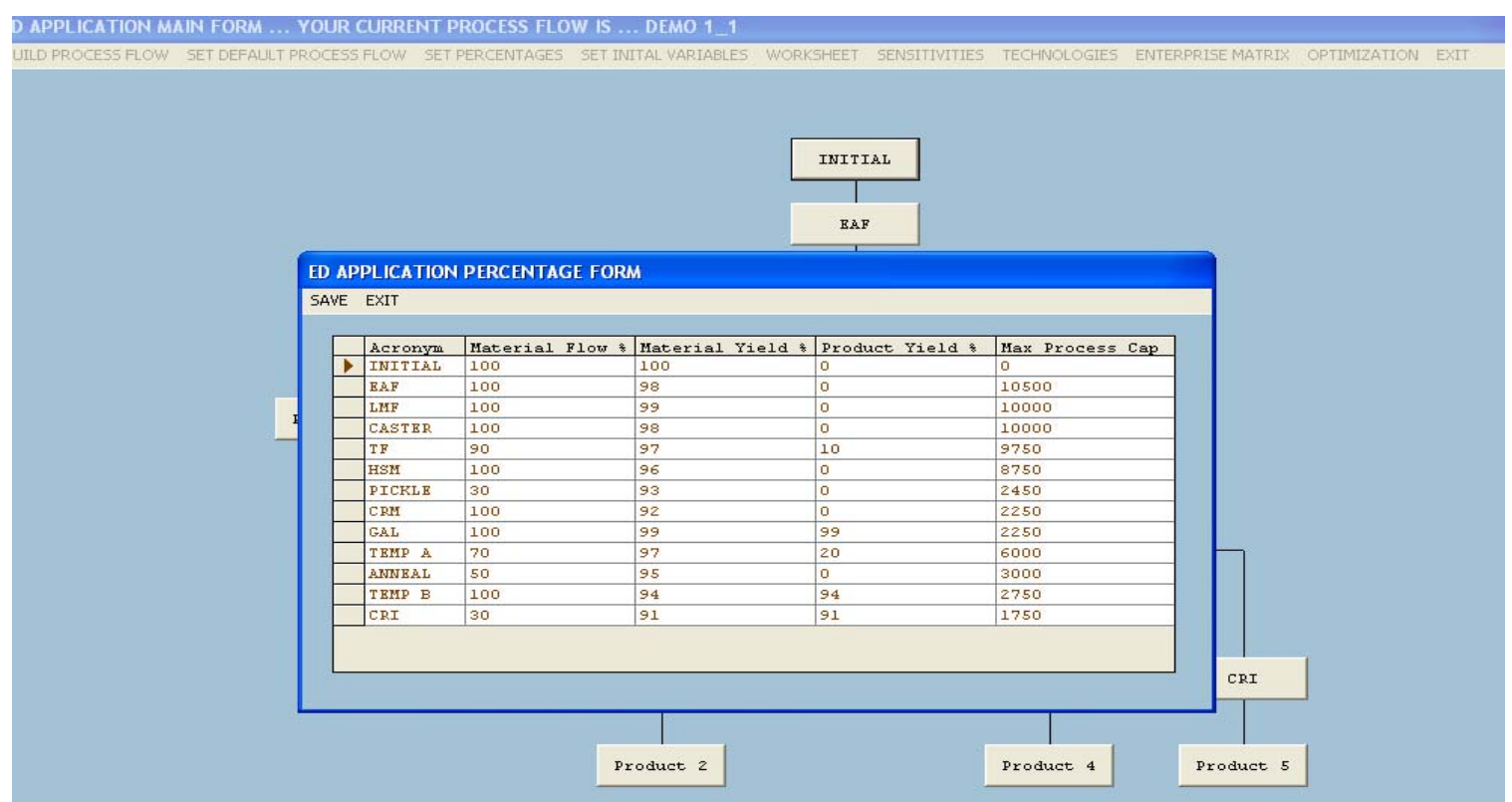

Fig. 7. The form for setting the material flow percentages.

For the third criterion requirement, the user must open the INITIAL VARIABLES FORM (Fig. 8) by clicking SET INITIAL VARIABLES in the combo box on the MAIN FORM (Fig. 1). The initial cost is any cost associated with starting the flow of material and is NOT the same cost the user will see on the process worksheet form. The initial material is the beginning material that will be introduced into the first process. The other variables are self explanatory and are used in the optimization routine.

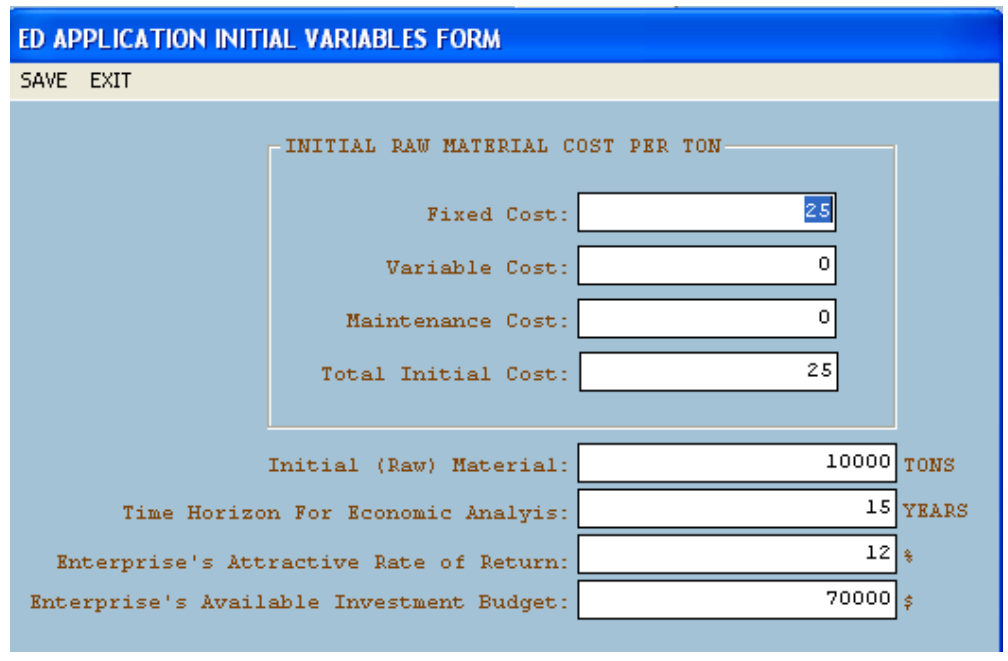

Fig. 8. Form for setting the initial variables.

The user then opens the WORKSHEET FORM. Two choices are provided for entering the worksheet information: individual or group. At this time, the only fields required are energy, 
cost, yield, and revenue - revenue only if the process has product. If the process being worked on has a product, the user can enter revenue on that product in the revenue field. If the process being worked on does not have a product the user is prevented from entering a revenue amount. If selecting the individual option (under the Worksheet tab), the user must click on the COST and or ENERGY buttons to open appropriate forms to enter the cost and energy values as sown in Figs. 9-11. If the group option (under the Worksheet tab) is selected, the user must click on VIEWS and then select either WORKSHEET, COST, or ENERGY to enter the appropriate data as shown in Figs. 12, 13.

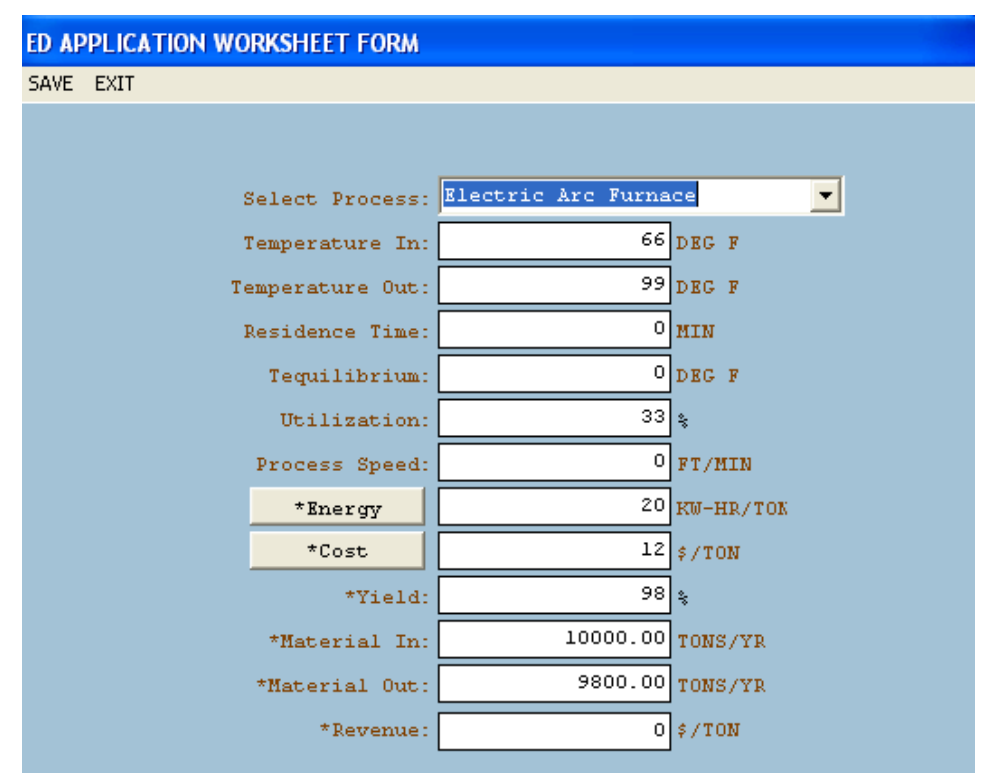

Fig. 9. User has selected the individual option (under the Worksheet tab) to enter workshe data. In this case the user must click the Energy and Cost buttons to enter that information.

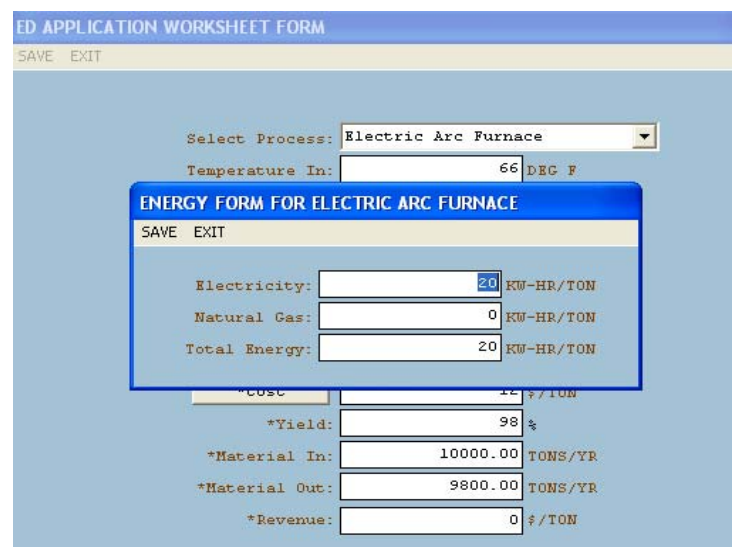

Fig. 10. User has selected the individual option (under the Worksheet tab) to enter worksheet data. This is the entry form for energy usage.

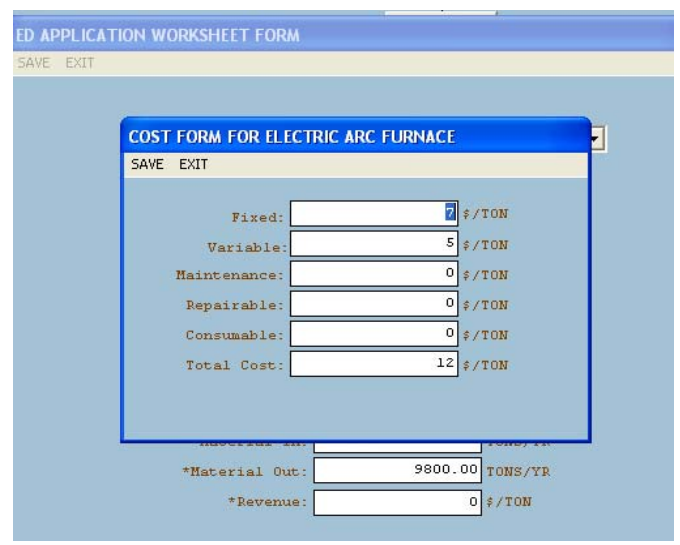

Fig. 11. User has selected the individual option (under the Worksheet tab) to enter worksheet data. This is the entry form for the costs. 


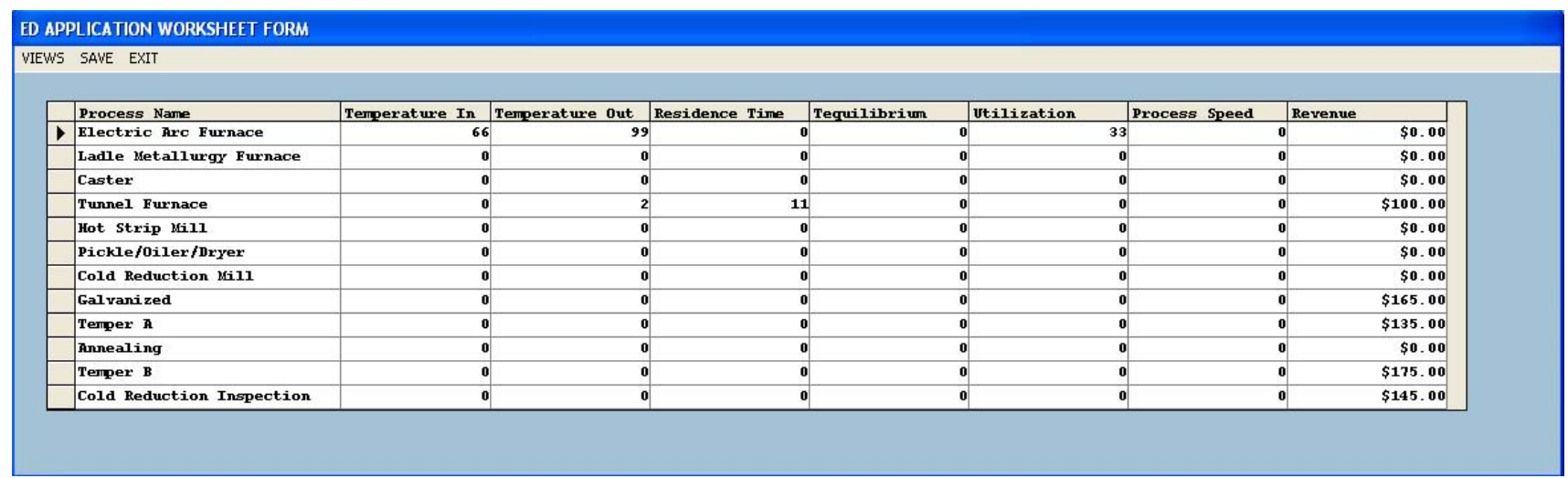

Fig. 12. User has selected the group option (under the Worksheet tab) to enter worksheet data. This is the entry form for costs.

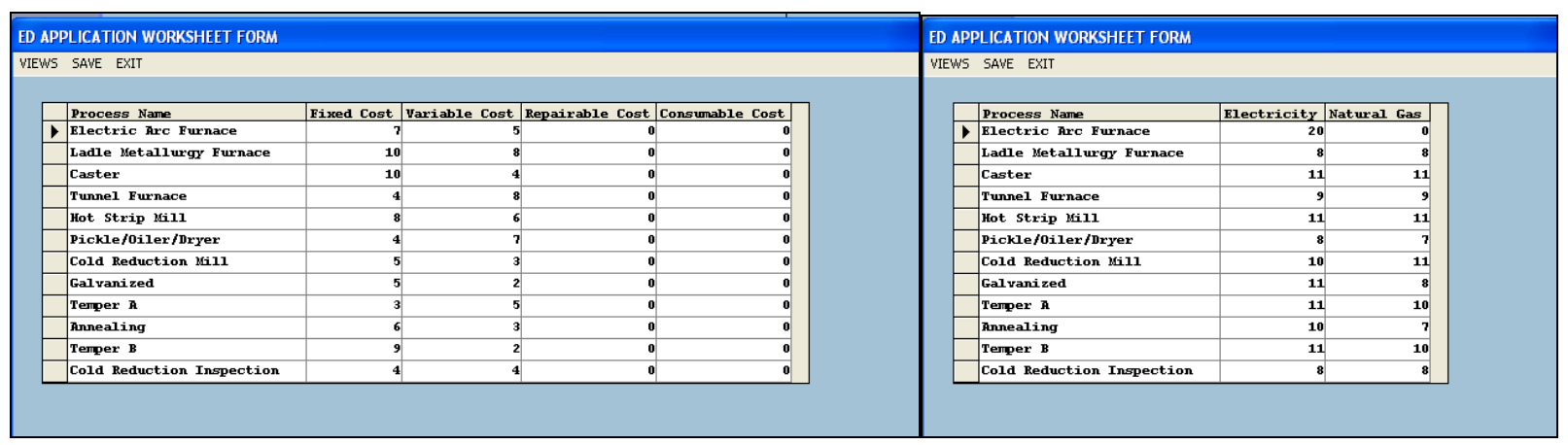

Fig. 13. User has selected the group option (under the Worksheet tab) to enter worksheet data. This is the entry form for energy usage.

The final criterion requirement is to fill in the additional technologies on the TECHNOLOGY ANALYSIS FORM. To open the TECHNOLOGY ANALYSIS FORM, click the TECHNOLOGIES button on the MAIN FORM. When the form opens (Fig. 5), the first process's technologies, if any, are automatically shown.

This criterion requirement is essential for the optimization routine. To add a new process variable, click on the ADD A ROW button on the TECHNOLOGY FORM. A new row will appear and the user can enter the new process variable, additional product, annual expense and investment. The variables cost, energy, efficiency, EC1 (1/electricity) and EC2 (1/natural gas) are calculated automatically.

To view the sensitivity parameters, click on the SENSITIVITIES button on the MAIN FORM to open the SENSITIVITIES FORM (Fig. 3). The table displays the sensitivity parameters associated with each process, where the sensitivity parameters are defined as:

DC/DP (or $\frac{\partial C}{\partial \mathrm{P}}$ ): cost to product sensitivity parameter (\$/ton).
DP/DE (or $\frac{\partial \mathrm{P}}{\partial E}$ ): product to energy sensitivity parameter (ton/kW-h). 
DE/Dn (or $\frac{\partial E}{\partial \eta}$ ): energy to efficiency sensitivity parameter (ton/kW-h).

Dn/DC (or $\frac{\partial \eta}{\partial C}$ ): efficiency to cost sensitivity parameter $\left(\$^{-1}\right)$.

DP/EC1: product to electricity sensitivity parameter (ton/kW-h).

DP/EC2: product to natural gas sensitivity parameter (ton/kW-h).

The user can choose to view a chart by choosing the desired sensitivity parameter by clicking the CHART button. Figure 14 below shows the chart for DC/DP for all process below the table of sensitivity values for all process.

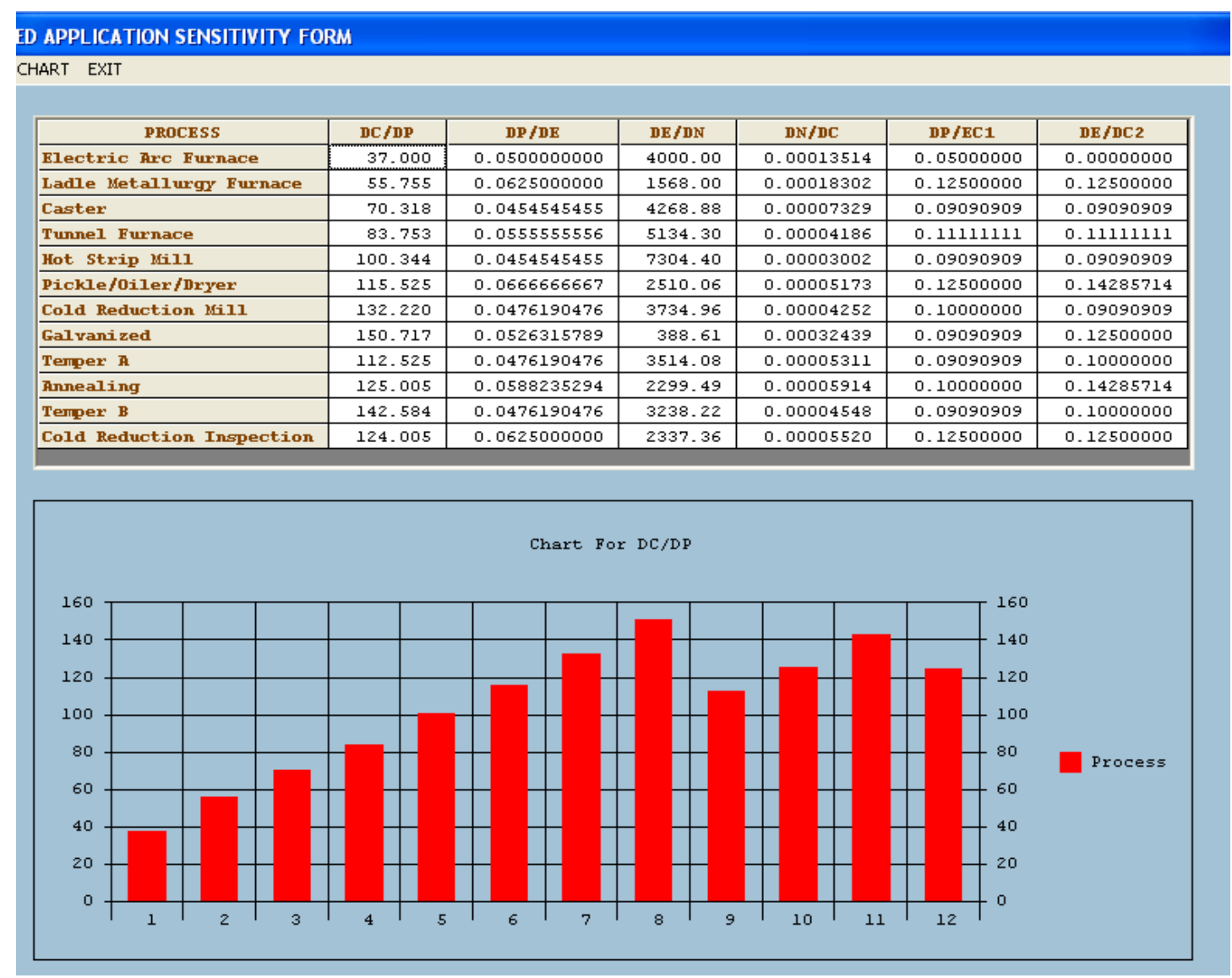

Fig. 14. Sensitivity table and chart of DC/DP for all processes.

To view the enterprise matrix, click on the ENTERPRISE MATRIX button on the MAIN FORM to open the ENTERPRISE MATRIX FORM. An overview of the basic EDA application is displayed. The top half shows the flow of material from one process to another while the bottom half shows the process parameters. At the right of the form, the product, revenue, and profit are displayed. Use the horizontal scroll bar to view the entire matrix. To view the ratio of material from one process to another, click on the VIEW MATERIAL RATIO button and the top half of the form reflects the material flow as a ratio. Figure 6 shows the EM and Fig. 15 below shows the enterprise-derivative RM. 


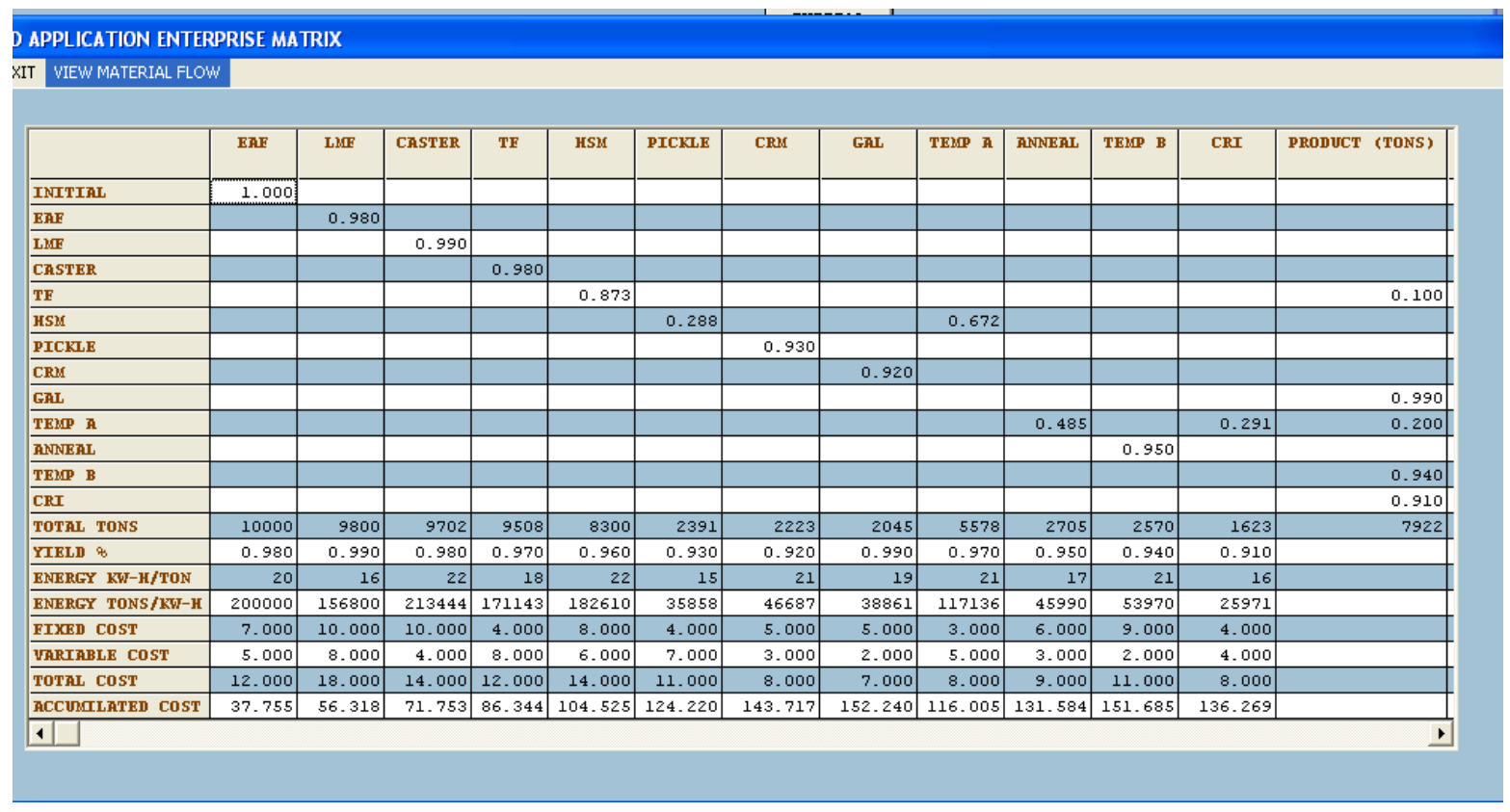

Fig. 15. Once the user has entered all the Enterprise information and the sensitivity parameters have been computed, the EM (products transferred from process to process in tons) or the RM (ratio of material moved from one process to the next) can be displayed. Here the RM is shown.

To run an analysis or optimization routine, click on the OPTIMIZATION button on the MAIN FORM. The user can run a risk analysis, alternative analysis or optimization \#1: increase throughput maximize profit. The RISK FORM (Fig. 16) shows the amount of increase in tons there will be per additional amount of product produced as well as energy and profit increases or decreases. The annual worth is a measure for $\mathrm{i}^{\text {th }}$ new operational strategy. The ALTERNATIVE ANALYSIS FORM (Fig. 17) shows the rankings of annual worth and energy used for each new operation strategy introduced.

The combo box on the optimization form allows the user to see the calculations needed to perform the optimization. For example, Fig. 18 shows the differences in the sensitivity parameters before and after optimization. The OPTIMIZED ENTERPRISE MATRIX FORM (Fig. 19) shows the new matrix flow due to the optimization. 


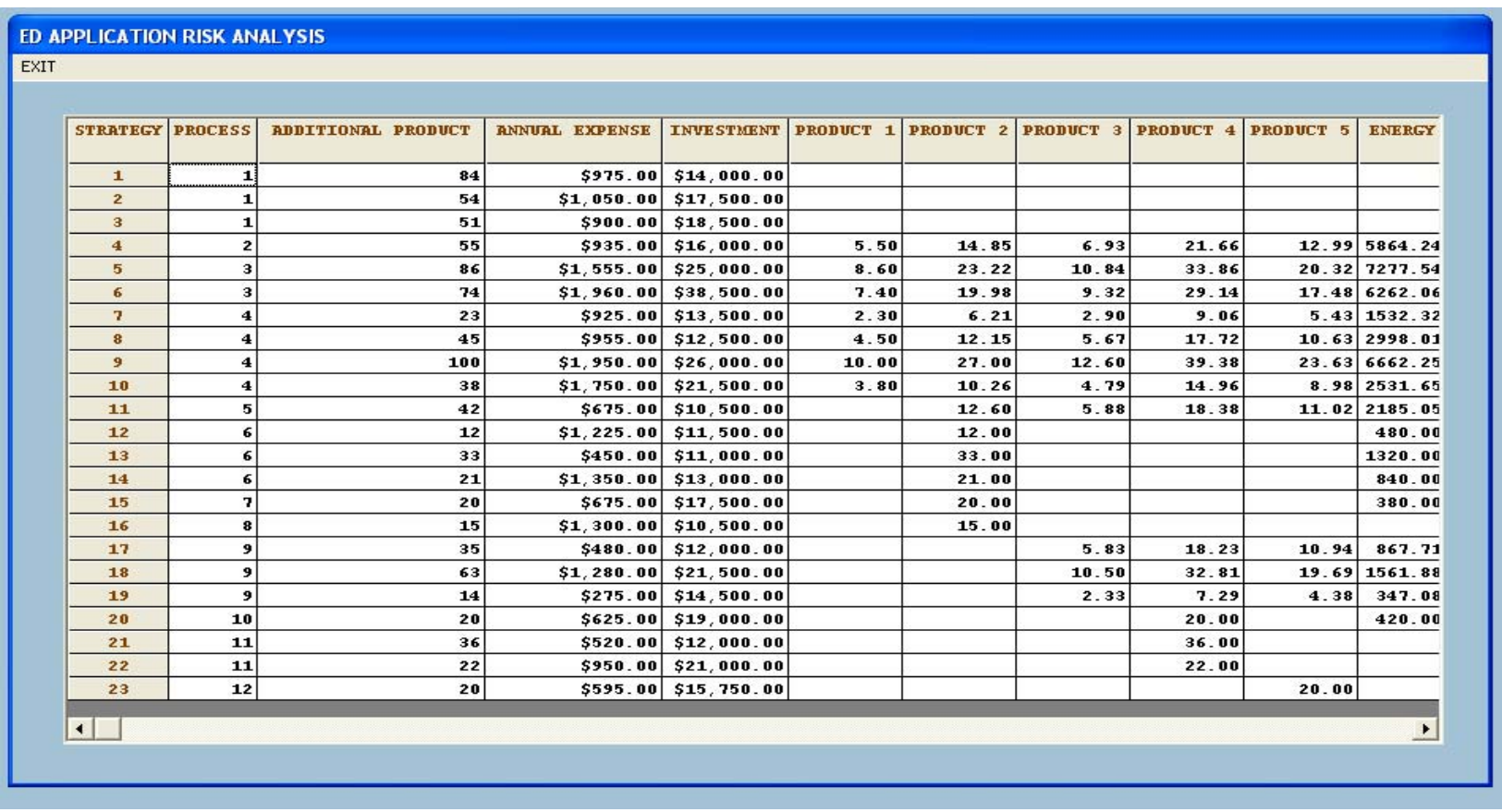

Fig. 16. RISK FORM showing the amount of increase in tons there will be per additional amount of product produced as well as energy and profit increases or decreases.

\begin{tabular}{|c|c|c|c|c|c|c|c|c|}
\hline \multicolumn{9}{|l|}{ EXIT } \\
\hline STRATEGY & PROCESS & ADDITIONAL PRODUCT & ARNUAL EXPPENSE & INUE STMENT & STRATEGY & ANNUAL WORTH & STRATEGY & ENERGY USED \\
\hline 1 & 7 & 84 & $\$ 975.00$ & $\$ 14,000.00$ & 2 & $(\$ 596,594.42)$ & 1 & \\
\hline 2 & 1 & 54 & $\$ 1,050.00$ & $\$ 17,500.00$ & 3 & $(\$ 596,591.25)$ & 2 & \\
\hline 3 & 1 & 51 & $\$ 900.00$ & $\$ 18,500.00$ & 1 & $(\$ 596,005.54)$ & 3 & \\
\hline 4 & 2 & 55 & $\$ 935.00$ & $\$ 16,000.00$ & 12 & $(\$ 1,113.48)$ & 16 & 1226225 \\
\hline 5 & 3 & 86 & $\$ 1,555.00$ & $\$ 25,000.00$ & 16 & $(\$ 366.65)$ & 21 & 1226225 \\
\hline 6 & 3 & $\mathbf{7 4}$ & $\$ 1,960.00$ & $\$ 38,500.00$ & 19 & $(\$ 359.37)$ & 22 & 1226225 \\
\hline 7 & 4 & 23 & $\$ 925.00$ & $\$ 13,500.00$ & 22 & $(\$ 183.31)$ & 23 & 1226225 \\
\hline 8 & 4 & 45 & $\$ 955.00$ & $\$ 12,500.00$ & 20 & $(\$ 134.66)$ & 19 & 1226572 \\
\hline 9 & 4 & 100 & $\$ 1,950.00$ & $\$ 26,000,00$ & 14 & $(\$ 108.72)$ & 15 & 1226605 \\
\hline 10 & 4 & 38 & $\$ 1,750.00$ & $\$ 21,500.00$ & 15 & $(\$ 84.42)$ & 20 & 1226645 \\
\hline 11 & 5 & 42 & $\$ 675.00$ & $\$ 10,500.00$ & 23 & $(\$ 7.48)$ & 12 & 1226705 \\
\hline 12 & 6 & 12 & $\$ 1,225.00$ & $\$ 11,500.00$ & 7 & $\$ 319.72$ & 14 & 1227065 \\
\hline 13 & 6 & 33 & $\$ 450.00$ & $\$ 11,000.00$ & 10 & $\$ 424.58$ & 17 & 1227093 \\
\hline 14 & 6 & 21 & $\$ 1,350.00$ & $\$ 13,000.00$ & 6 & $\$ 1,881.28$ & 13 & 1227545 \\
\hline 15 & 7 & 20 & $\$ 675.00$ & $\$ 17,500.00$ & 17 & $\$ 2,869.57$ & 7 & 1227757 \\
\hline 16 & 8 & 15 & $\$ 1,300.00$ & $\$ 10,500.00$ & 13 & $\$ 2,884.93$ & 18 & 1227787 \\
\hline 17 & 9 & 35 & $\$ 480.00$ & $\$ 12,000.00$ & 4 & $\$ 3,002,17$ & 11 & 1228410 \\
\hline 18 & 9 & 63 & $\$ 1,280.00$ & $\$ 21,500.00$ & $\mathbf{8}$ & $\$ 3,523.08$ & 10 & 1228757 \\
\hline 19 & 9 & 14 & $\$ 275.00$ & $\$ 14,500.00$ & 21 & $\$ 4,018.11$ & 8 & 1229223 \\
\hline 20 & 10 & 20 & $\$ 625.00$ & $\$ 19,000.00$ & 11 & $\$ 4,451.90$ & 4 & 1232089 \\
\hline 21 & 11 & 36 & $\$ 520.00$ & $\$ 12,000.00$ & 18 & $\$ 4,763.90$ & 6 & 1232487 \\
\hline 22 & 11 & 22 & $\$ 950.00$ & $\$ 21,000.00$ & 5 & $\$ 5,807,98$ & 9 & 1232887 \\
\hline 23 & 12 & 20 & $\$ 595.00$ & $\$ 15,750.00$ & 9 & $\$ 8,262.32$ & 5 & 1233503 \\
\hline
\end{tabular}

Fig. 17. ALTERNATIVE ANALYSIS FORM shows the rankings of annual worth and energy used for each new operation strategy introduced. 


\section{ED APPLICATION ... VIEW CHANGES IN PROCESS PARAMETERS AFTER OPTIMIZATION 1}

EXIT

*RED SIGNIFIES A DECREASE *BLUE SIGNIFIES AN INCREASE

please choose a grid from below

View Changes In process parameters After Optimization 1 -

\begin{tabular}{|c|c|c|c|c|c|c|c|c|c|c|c|c|}
\hline Process & 1 & 2 & 3 & 4 & 5 & 6 & 7 & 8 & 9 & 10 & 11 & 12 \\
\hline P Oxiginal & 10000 & 9800 & 9702 & 9508 & 8300 & 2391 & 2223 & 2045 & 5578 & 2705 & 2570 & 1623 \\
\hline P New & 10000 & 9800 & 9702 & 9508 & 8341 & 2415 & 2246 & 2066 & 5635 & 2782 & 2643 & 1669 \\
\hline p Change & & & & & 41 & 24 & 23 & 21 & 57 & 77 & 73 & 46 \\
\hline Y Oxiginal & 0.980 & 0.990 & 0.980 & 0.970 & 0.960 & 0.930 & 0.920 & 0.990 & 0.970 & 0.950 & 0.940 & 0.910 \\
\hline$Y$ New & 0.980 & 0.990 & 0.980 & 0.975 & 0.965 & 0.930 & 0.920 & 0.990 & 0.988 & 0.950 & 0.954 & 0.910 \\
\hline Y Change & & & & 0.005 & 0.005 & & & & 0.018 & & 0.014 & \\
\hline E Original & 200000 & 156800 & 213444 & 171143 & 182610 & 35858 & 46687 & 38861 & 117136 & 45990 & 53970 & 25971 \\
\hline E New & 200000 & 156800 & 213444 & 171143 & 183501 & 36223 & 47162 & 39257 & 118328 & 47299 & 55507 & 26710 \\
\hline E Change & & & & & 891 & 365 & 475 & 395 & 1192 & 1309 & 1537 & 739 \\
\hline Ft Oxiginal & 7.000 & \begin{tabular}{|l|}
10.000 \\
\end{tabular} & $10.000 \mid$ & 4.000 & 8.000 & 4.000 & 5.000 & 5.000 & 3.000 & 6.000 & 9.000 & 4.000 \\
\hline Ft New & 7.000 & 10.000 & 10.000 & 4.100 & 8.081 & 4.000 & 5.000 & 5.000 & 3.312 & 6.000 & 9.197 & 4.000 \\
\hline Ft Change & & & & 0.100 & 0.081 & & & & 0.312 & & 0.197 & \\
\hline ACT Oxiginal & 37.8 & 56.3 & 71.8 & 86.3 & 104.5 & 124.2 & 143.7 & 152.2 & 116.0 & 131.6 & 151. ? & 136.3 \\
\hline ACT New & 37.8 & 56.3 & 71.8 & 86.0 & 103.7 & 123.4 & 142.8 & 151. 3 & 113.5 & 128.9 & 146.9 & 133.5 \\
\hline ACT Change & & & & -0.3 & -0.8 & -0.9 & -0.9 & -0.9 & -2.5 & -2.7 & -4.8 & -2.8 \\
\hline
\end{tabular}

Fig. 18. Differences in the sensitivity parameters before and after optimization.

\begin{tabular}{|c|c|c|c|c|c|c|c|c|c|c|c|c|c|c|c|}
\hline \multicolumn{14}{|c|}{ APPLICATION ... VIEW OPTIMIZED ENTERPRISE MATRIX } & \multicolumn{2}{|c|}{ APPLICATION ... VIEW OPTIMIZED ENTERPRISE MATRIX } \\
\hline \multicolumn{16}{|c|}{ *RED SIgnipirs a drCREasB *BLUR SIGNipibs an INCRBasB } \\
\hline \multicolumn{16}{|c|}{ Please choose a grid from below } \\
\hline \multicolumn{6}{|c|}{ Viev Optimized Bnterprise llatrix } & 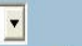 & & & & & & & & & \\
\hline & EAP & LIIF & CASTER & $\mathrm{TP}$ & HSM & PICKLE & CRMI & GAL & TEMP A & ANNERL & TEMP B & CRI & PRODUCT (TONS) & REVENUE (\$/TON) & PROFIT (\$/TON) \\
\hline INITIRL & 10000 & & & & & & & & & & & & & & \\
\hline $\mathrm{EAP}$ & & 9800 & & & & & & & & & & & & & \\
\hline LIS & & & 9702 & & & & & & & & & & & & \\
\hline CASTER & & & & 9508 & & & & & & & & & & & \\
\hline $\mathrm{TF}$ & & & & & 8341 & & & & & & & & 927 & $\$ 100.00$ & $\$ 12,949.36$ \\
\hline HSM & & & & & & 2415 & & & 5635 & & & & & & \\
\hline PICKLE & & & & & & & 2246 & & & & & & & & \\
\hline $\mathrm{CRM}$ & & & & & & & & 2066 & & & & & & & \\
\hline GAL & & & & & & & & & & & & & 2045 & $\$ 165.00$ & $\$ 28,012.91$ \\
\hline TELP 凡 & & & & & & & & & & 2782 & & 1669 & 1113 & $\$ 135.00$ & $\$ 23,977.39$ \\
\hline ANNEAL & & & & & & & & & & & 2643 & & & & \\
\hline TEMP B & & & & & & & & & & & & & 2522 & $\$ 175.00$ & $\$ 70,980.57$ \\
\hline$\overline{\mathrm{CRI}}$ & & & & & & & & & & & & & 1519 & $\$ 145.00$ & $\$ 17,519.38$ \\
\hline TOTAL TONS & 10000 & 9800 & 9702 & 9508 & 8341 & 2415 & 2246 & 2066 & 5635 & 2782 & 2643 & 1669 & 8126 & $\$ 720.00$ & $\$ 153,439.61$ \\
\hline YIELD \& & 0.980 & 0.990 & 0.980 & 0.975 & 0.965 & 0.930 & 0.920 & 0.990 & 0.988 & 0.950 & 0.954 & 0.910 & & & \\
\hline ENERGY $\mathrm{KW}$-H/TON & 20 & 16 & 22 & 18 & 22 & 15 & 21 & 19 & 21 & 17 & 21 & 16 & & & \\
\hline ENERGY TONS/KW-H & 200000 & 156800 & 213444 & 171143 & 183501 & 36223 & 47162 & 39257 & 118328 & 47299 & 55507 & 26710 & 1295374 & & \\
\hline FIXED COST & 7.000 & 10.000 & 10.000 & 4.100 & 8.081 & 4.000 & 5.000 & 5.000 & 3.312 & 6.000 & 9.197 & 4.000 & & & \\
\hline VARIABLE COST & 5.000 & 8.000 & 4.000 & 8.000 & 6.000 & 7.000 & 3.000 & 2.000 & 5.000 & 3.000 & 2.000 & 4.000 & & & \\
\hline TOTAL COST & 12.000 & 18.000 & 14.000 & 12.100 & 14.081 & 11.000 & 8.000 & 7.000 & 8.312 & 9.000 & 11.197 & 8.000 & & & \\
\hline ACCUSLLATED COST & 37.755 & 56.318 & 71.753 & 86.027 & 103.733 & 123.369 & 142.792 & 151.305 & 113.455 & 128.901 & 146.851 & 133.468 & & & \\
\hline
\end{tabular}

Fig. 19. OPTIMIZED ENTERPRISE MATRIX FORM shows the new matrix flow due to the optimization. 


\section{CONCLUSIONS}

In the new economy, companies will be looking at R\&D investments as a means to increase market share and equity along with revenue, profit, and dividends. They will be concerned with understanding the technology's complete impact, what its total cost of ownership will be, and what the uncertainty and risk associated its R\&D investments is. In light of this, companies will be looking for ways to reduce or eliminate these risks. The EDA based on MS Access, will help in this by making available to these companies new tools for developing and managing investment strategies and risks.

The benefits derived from conducting an energy-derivative analysis using EDA are many and include:

- Quantifying the impact that a particular technology has in a plant in terms of economic benefits, energy saved, efficiency increases, and product gains.

- Providing metrics for a strategic decision making process.

- Identifying unique parameters that can be used to characterize a system's performance.

- Contrasting and comparing different technologies for a particular process or across the enterprise.

- Selecting best technology mix based on a set of criteria (optimization).

- Calculating total impact on an enterprise and total cost of ownership.

- Tracking process and economic impact over time.

- Strategizing (risk management) based on expectations.

An energy-derivative analysis can have a major impact on how companies manage risk and make R\&D investment decisions in the future.

The Enterprise Derivative Application is an MS Access application which implements energyderivative analysis for optimization of an industrial process. It is a tool to help industry planners choose the most productive way of making their products while minimizing their cost. Based on the calculation of Enterprise-Derivative sensitivity parameters, the EDA can display a particular sensitivity or all sensitivities can be compared for all processes. This was shown for a specific application of a steel mini mill production process.

Energy-derivative analysis was demonstrated to be flexible enough to be applied to many other industrial processes besides the steel process shown here. Examples of processes where energyderivative analysis would prove useful are:

- Wireless monitoring of processes in the petroleum cracking industry;

- Wireless monitoring of motor failure for determining the optimum time for replacement of parts;

- Optimizing the air-transport of cargo; and

- Optimizing the design of new military material design and deployment strategies (e.g., Future Combat Systems).

A particular advantage of the MS Access-based application is its flexibility in defining the process flow and establishing the relationships between parent and child process and between processes and products. The application can be easily modified to apply to many different industrial and organizational environments. Another advantage is the flexibility of defining sensitivity parameters. Sensitivities can be determined between all possible variables in the process flow as a function of time. The dynamic 
development of the process can be tracked over time and optimized. The energy-derivative analysis is a uniquely flexible and efficient way for planners to choose the most productive way of optimizing production while minimizing costs. The MS Access-based EDA is a particularly flexible and robust implementation of energy-derivative analysis and it should prove useful in the analysis and optimization of industrial processes. 


\section{REFERENCES}

${ }^{1}$ G. O. Allgood and W. W. Manges, (2001) "Value Chain Analysis (Value-Derivative) Model for the Steel Industry”, Phase II Project Report for the U. S. Department of Energy, Office of Industrial Technologies.

${ }^{2}$ J. A. Torres (2002) “An Integrated Value-Derivative Model for the Steel Industry to Evaluate and Optimize the Impact of Operational Strategies using Total Enterprise Performance Indicators”,

Dissertation for Doctor of Philosophy Degree, University of Tennessee, Knoxville, May, 2002.

${ }^{3}$ G. O. Allgood, J. Knox, and R. C. Ward, "Enterprise Derivative Application: Flexible Software for Optimizing Production while Minimizing Costs,” Proceedings of MARCON 2005: The University of Tennessee Maintenance and Reliability Conference (MARCON), Knoxville, Tennessee, USA, May 3-6, 2005. 

APPENDIX A: SET UP FORM FOR EDA 


\section{APPENDIX A: SET UP FORM FOR EDA}

Before the application can be used, the user must work through a series of steps to ensure the application works correctly. This user's guide will walk the user through the steps of determining the parent-child relationships. The parent-child relationships determine the flow of product from one process to another as well as any final product.

To begin, open the EDA.mdb database. The MAIN FORM will open (Fig. 1). The form shows the default process flow, in this case DEMO 1_1, as indicated in the forms caption bar. To create a new process flow, click on the BUILD PROCESS FLOW button at the top left of the form.

On the SET UP form (Fig. A1) the user can build a process flow or load an existing process flow to work with. This figure shows the options available when the user clicks on the BUILD PROCESS FLOW button. The user is guided through the order from determining the processes/products to saving the process flow diagram. If a problem occurs, any part of the process can be reset. Following the given steps is self explanatory and once the user saves the process flow and clicks on the EXIT button, they can begin populating their process flow as given in the process flow overview.

The first step in building a process flow is to specify the number of processes and products as seen in Fig. A2. Click on the Go menu option (Fig. A1) under the Determine Processes/Products pull-down menu item, and enter the number of process and products needed for the process flow (Fig. A2). The number of products can not exceed the number of processes.

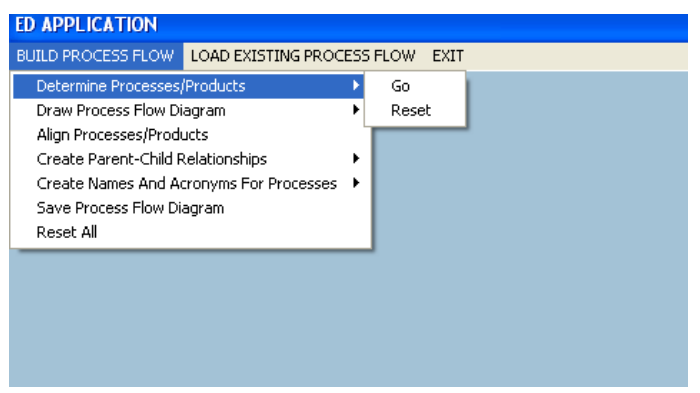

Fig. A1. SET UP FORM for building a process flow or loading a previously built process.

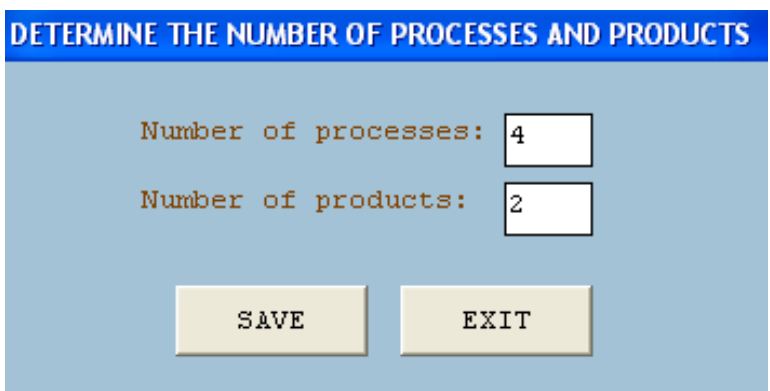

Fig. A2. Enter the number of processes and products.

Once these have been saved, the next step is to draw the process flow diagram. Upon choosing the Draw Process Flow Diagram pull-down menu item and selecting Start option (Fig. A3), a grid appears with buttons to the left (Fig. A4). Draw the process flow diagram as you want it to appear on the main form. How it is drawn here is how it will look. Simply drag each button to a place on the grid and drop it. It is not important to exactly align the buttons; this will be done later; for now just get each button approximately aligned. Be sure to place the numbers in numerical order as seen in Fig. A5. 


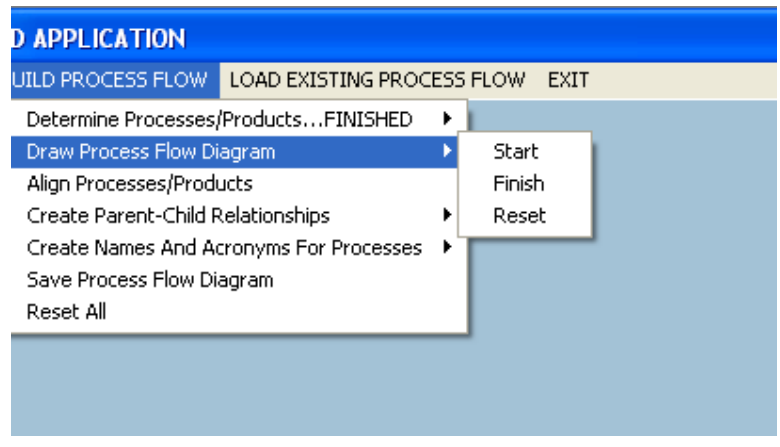

Fig. A3. To get the grid for creating the process flow, click on the Start

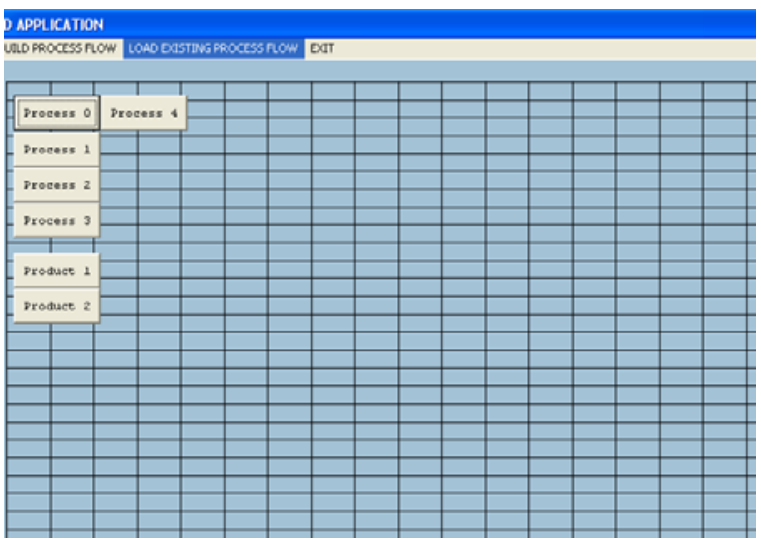

Fig. A4. Grid for creating the process flow.

Once the user is finished with drawing the process flow diagram, click on the Align Processes/Products pull-down to provide the aligned process flow (Fig. A5).

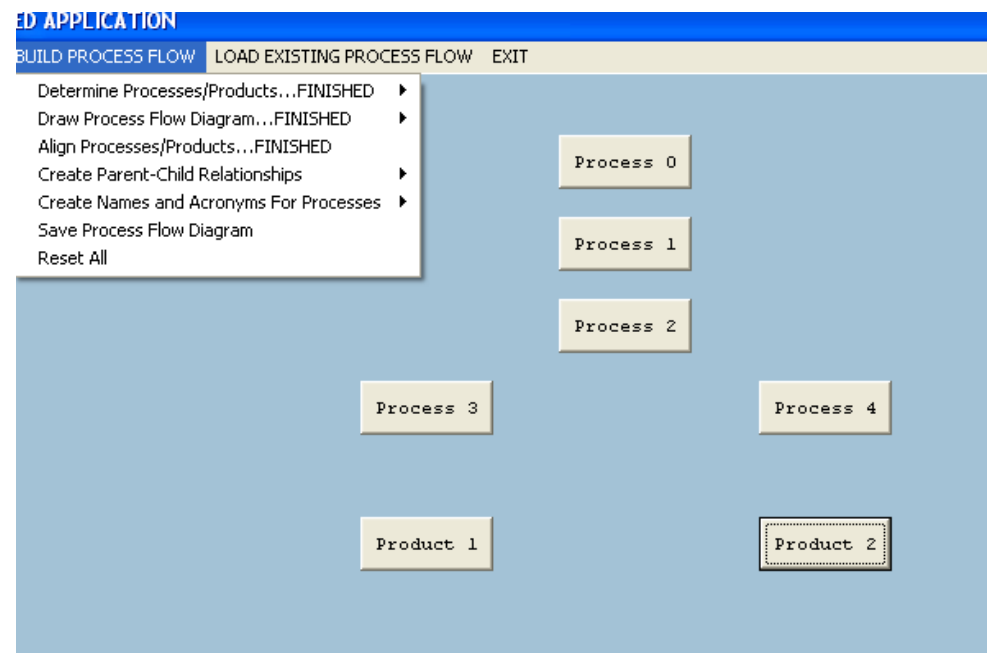

Fig. A5. Process flow after placing processes and products on the grid.

To create parent child relationships, simply choose that option on the pull-down menu (Fig. A6) and click first on the parent and click on the child. A line will be drawn connecting the two, signifying the relationship has been made. You do not have to create the relationships in order. 


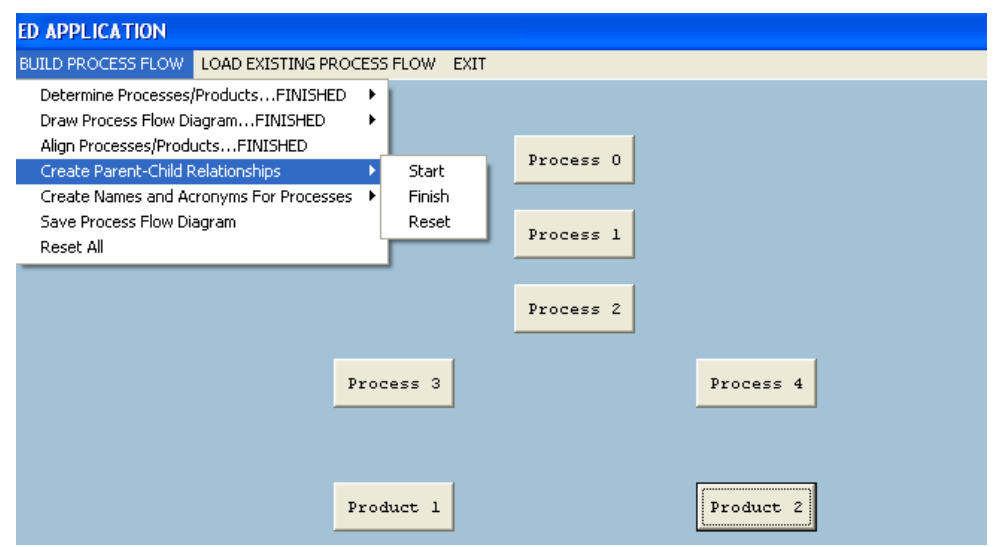

Fig. A6. Select Create Parent-Child Relationships from pull-down menu.

The next step is to assign names and acronyms to processes. The user chooses the pull-down menu option Create Names and Acronyms for Processes (Fig. A7), then selects Create, and fills in the names and acronyms for the processes as shown in Fig. A8.

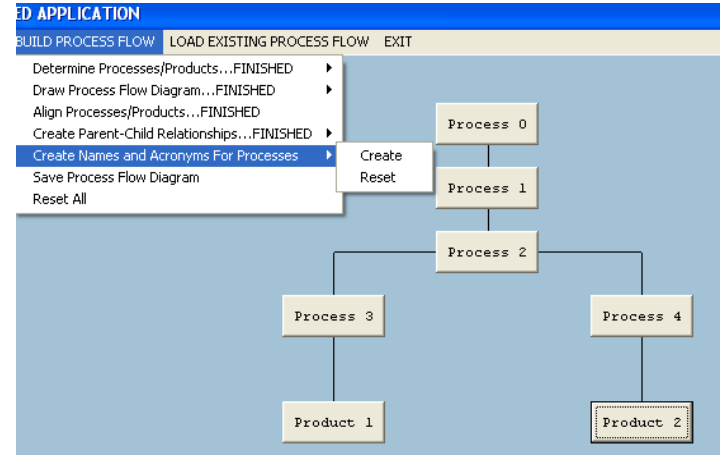

Fig. A7. Select Create Names and Acronyms for Processes

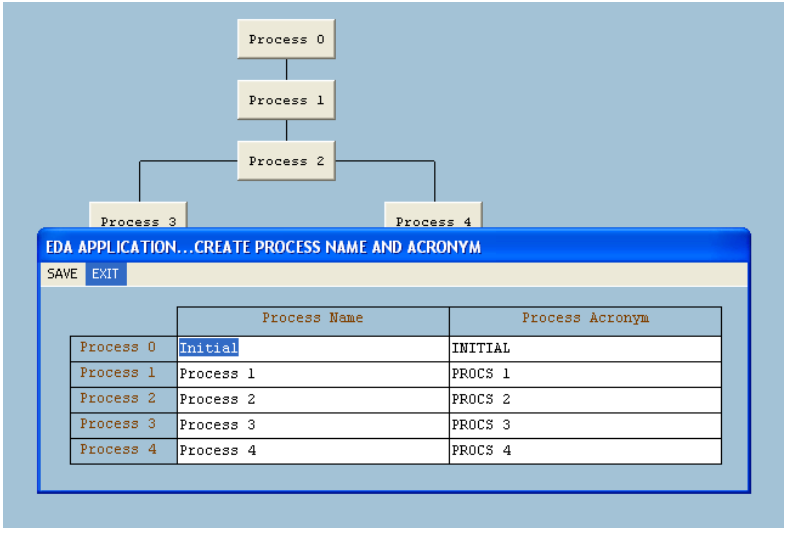

Fig. A8. Entering names and acronyms for processes.

The completed process flow diagram is shown in Fig. A9. The last step is to save the process flow diagram information by clicking on the pull-down item Save Process Flow Diagram. At this time, enter a name for the new process flow. The user can now exit out of the Build Process Flow feature and start populating the newly created process flow diagram. 


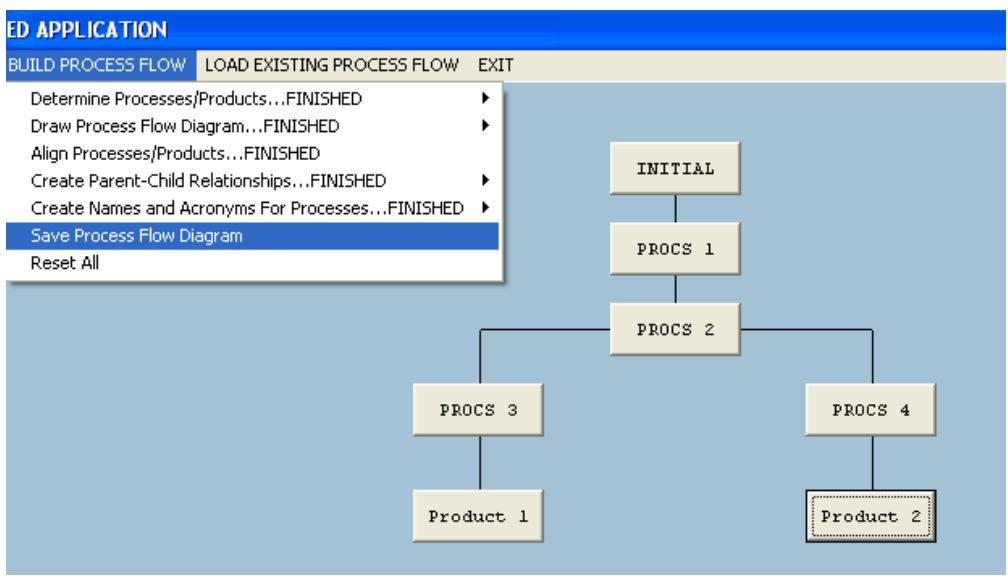

Fig. A8. Final process flow diagram. User can now save the diagram and exit the process flow set-up. 

APPENDIX B: FIX FOR RUNNING APPLICATION 


\section{APPENDIX B: FIX FOR RUNNING APPLICATION}

We ran into a problem implementing the EDA on machines that did not have Visual Basic installed. On these machines you may get the error that certain system routines are missing (in our case the routine was mschrt20.ocx). The failure occurred when selecting the menu item Sensitivities which is using charting capability to chart the sensitivity values for all processes. This was corrected by downloading the routine (mschrt20.ocx) and moving it to the C:IWindows $\backslash$ System32 directory. The file must be registered using the following command:

$$
\text { C:IWindows } \backslash \text { System32>regsvr32 mschrt20.ocx }
$$

mschrt20.ocx was obtained from this site:

http://www.ocxdump.com/download-ocx-files_new.php/ocxfiles/M/mschrt20.ocx/6.00.81774/download.html .

This fixed the problem and we were able to successfully run the application and produce the charts. 